\title{
A qualitative study of how doctors use impression management when they talk about stress in the UK
}

\author{
Neill J. Thompson ${ }^{1}$, Sally S. Corbett ${ }^{2}$, Mark Welfare ${ }^{2}$ \\ ${ }^{1}$ Department of Psychology, Northumbria University, UK \\ ${ }^{2}$ Northumbria Healthcare NHS Foundation Trust, UK \\ Correspondence: Neill J. Thompson, Department of Psychology, Northumbria University, 150, Northumberland Building \\ Newcastle upon Tyne, NE1 8ST. Email: Neill.thompson@northumbria.ac.uk
}

Accepted: November 02, 2013

\begin{abstract}
Objective: To examine how junior doctors talk about experiences and perceptions of stress in order to better understand the socio-cultural influences of stress in medical education.

Method: In depth semi-structured interviews were conducted with 10 doctors who were at the end of the first year of the UK Foundation Programme (FY1, equivalent to the intern year). A discourse analysis approach was used to analyse the findings.

Results: Participants were found to typically normalise, deflect or trivialise their own experiences of stress. Consistent patterns of talking about stress; 'busyness', 'patient responsibility' and being the 'good doctor' were identified. These patterns formed interpretive repertoires that can be viewed as functioning as a form of impression management. The repertoires allow doctors to talk about their views and
\end{abstract}

experiences of stress as a wider professional issue, without risk of being judged on how an inability to cope with stress might reflect on their own performance as a doctor.

Conclusions: Consistent patterns of talking about stress exist in medical education and shape individual and organisational responses. Doctors who are not coping with stress may risk increased harm by not seeking help as a consequence of prolonging attempts to maintain the impression of coping. Greater sensitivity is required where stress is simply constructed as an environmental factor or where those who admit to not coping become marginalised. Medical educators require greater awareness of the dominant stress repertoires employed within their organisation.

Keywords: Impression management, stress, discourse analysis, coping, junior doctors, foundation programme

\section{Introduction}

Internationally, despite the variations across medical education settings, junior doctors consistently report experiencing high levels of stress. ${ }^{1-8}$ The volume of studies designed to measure stress levels is in contrast to the lack of studies that describe validated interventions designed to address doctors' stress. The 'medical culture' and doctors' own expectations further contribute to the difficulty in managing stress. ${ }^{9}$ During medical education doctors may prioritise learning over personal wellbeing. ${ }^{10}$ Doctors are often reluctant to admit personal illness or seek help. ${ }^{11-14}$ Doctors typically respond to illness by continuing to work. $^{15,16}$ It has also been found that doctors can be reluctant to seek help for 'less defined' illnesses, such as stress. ${ }^{17}$ Collectively, these factors may mask the actual prevalence of observable and reported stress in practice. In general people who experience significant levels of stress and anxiety may be reluctant to present to support services because of the stigma attached to psychiatric illness. ${ }^{18}$ An idealised view persists that good doctors do not make mistakes and that illness, particularly mental illness, is a weakness. ${ }^{19}$ Early career doctors report a fear of being tarnished with the stigma of being "the stressed one" because of the implications this will have on how they are perceived professionally. ${ }^{20}$ In general doctors are reluctant to label themselves as 'stressed'. ${ }^{21}$ Any admission of not coping may present further concerns about performance, which may lead to a risk of regulatory involvement, an associated threat to reputation, professional identity or ultimately the end to the doctors' career. In this study we adopt a general conceptualisation used by Bicknell and Liefooghe ${ }^{22}$ of stress:

\footnotetext{
"as a psychological disharmony that arises through psychological (and potentially physical) interactions with the environ-
} 
ment. The way disharmony is constructed and accounted for by individuals is, however, mediated through discourse."

The definition is founded on a social constructionist standpoint, whereby stress is constructed within the social context it inhabits and the 'stressed individual' is allocated responsibility for any subsequent outcome. ${ }^{23,24}$ Thus, stress is viewed as a social condition in which the individual becomes accountable for their predicament. ${ }^{25,26}$ This viewpoint offers an insight into the position doctors may face whereby they are accountable for their own stress.

Perceiving someone as accountable for how they deal with stress creates a stake for the individual. At stake is being seen as someone who is less able to cope with the stress compared with others, which is of concern within medical education where not coping can be associated with not performing as well compared others. ${ }^{14}$ For the doctor, performance and competence are the outward and visible expression of professionalism. ${ }^{27}$ Therefore, there is a need to be able to manage the impression of coping as a means of maintaining this expression of professionalism. Impression management was defined by Goffman ${ }^{28}$ as:

\footnotetext{
"the conscious or unconscious orchestration of a carefully designed presentation of self that will create an opinion that fits your goals or needs in a social interaction."
}

For example, a way that professionalism can be lost might be when the doctor is viewed as not coping with stress. Therefore, doctors need to demonstrate to their peers and supervisors that stress is not affecting performance. ${ }^{29}$ Impression management strategies are likely to be introduced to maintain this sense the presentation of coping with stress, in order to be seen as performing to the same standard others. Goffman ${ }^{28}$ makes a distinction been between the expressions 'given' and 'given off:

"knowing that the individual is likely to present himself in a light that is favourable to him, the others may divide what they witness into two parts; a part that is relatively easy for the individual to manipulate at will, being chiefly his verbal assertions, and a part in regard to which he seems to have little concern or control, being chiefly derived from the expressions he gives off."

A possible implication of this is that the management of the impression, of being a model professional who can cope, is prioritised over the need to seek help as this could lead to becoming socially positioned as the doctor who cannot cope. A doctors' decision to seek help and support for stress may not be dictated by recognising a concern for their own health. Instead help-seeking might be initiated when they can no longer manage a social impression of coping, when expressions given off to witnesses fail to sustain the impression of coping. This suggests that any social constructions of stress may incorporate a degree of impression management. The extent that this is likely to be determined will be through the use of particular discourses.
Discourses are consistent patterns of talking which perform a social function. The stress discourse is a historically, socially and institutionally specific structure of statements, terms, categories and beliefs that are embedded in institutions social relationships and texts. ${ }^{30}$ Such discourses have been found in other professions, such as police, teachers and clerical workers. ${ }^{31-33}$ Within medical education a 'hidden curriculum' has often been reported. ${ }^{34}$ That the hidden curriculum is often referred to does reinforce the existence and influence of socio-cultural factors. These factors may indicate that a set of doctor specific stress discourses could evolve through socialisation during training.

Socio-culturally embedded discourses can be significant as they can be influential on how employees complain about stress and how the organisation responds. ${ }^{35}$ Any strategy to reduce the stress levels experienced by junior doctors could be undermined by socio-cultural factors such as dominant stress discourses. Firstly, doctors as individuals may not respond to health concerns and resist help-seeking by masking any concern through impression management that they are coping. Secondly, the medical education culture may contain social prejudices where failure to cope with stress potentially leads to stigmatisation. Previous studies in this area may have therefore been limited through their failure to consider the socio-cultural context that doctors' stress inhabits.

The aim of the study was to examine how junior doctors talk about experiences and perceptions of stress in order to better understand socio-cultural influences in medical education. The implications that this might have for organisational interventions intended to prevent or alleviate stress are to be also considered.

\section{Conceptual framework}

The rationale for using a discourse analysis approach in this study is that stress is a social phenomenon and generally takes place within an interactive context; such as a disclosure to a colleague or supervisor of 'being stressed' or not coping. Discourse analysis allows an examination of how stress can be socially constructed and perpetuated through social and historic messages, organisational or professional communication and perpetuated by organisational practices. ${ }^{23}$ It is appropriate as an analytic approach for examining topics such as impression management or socio-cultural factors, often referred to as the hidden curriculum, ${ }^{34}$ which are also socially constructed. As an approach discourse analysis is interested in how people use language purposefully in everyday interactions and places the speaker as active in constructing discourses in order to achieve goals within those social interactions. ${ }^{36}$ Within this setting the talk of the doctor is analysed and the potential goals of using constructed discourses, such as managing being viewed as 'stressed', or subsequent outcomes of their usage are examined. 
The approaches to discourse analysis are wide ranging (e.g. identifying codes; language properties and linguistics, use and interaction; conversational analysis and ethnomethdology, interpretative repertoires and societal discursive practices; studies of discourse and power). ${ }^{37}$ This study centred on understanding the interpretative repertoires that the doctors employ. The origins of discourse analysis here are more aligned to the discursive psychology analytic method $^{38}$ rather than critical discourse analytic approaches. ${ }^{39,40}$ As such the focus becomes the language use in this particular socio-cultural context rather than the context of a particular interaction.

A central concern in the analysis was to look for different shared interpretative repertoires used by the doctors as they provide descriptions and accounts of doctors' stress and presented themselves as coping, or not coping, with stress. Potter and Wetherell ${ }^{38}$ define interpretative repertoires as: "recurrently used systems of terms used for characterizing and
evaluation actions, events and other phenomena."

The specific function which they serve is to enable the justification of particular versions of events, to excuse or validate their own behaviour, to fend off criticism or otherwise allow them to maintain a credible stance in an interaction $^{41}$. Interpretative repertoires are not considered entrenched attitudes; different repertoires might be used by the same doctor for different context and different functions; this current study therefore focused on the specific medical education context.

\section{Methods}

A purposive sample was adopted by writing, through the hospital internal postal system, to all 42 FY1 doctors in a single UK National Health Service Trust. A follow up reminder email was sent one week later. The initial written invitation and the follow-up email contained detailed information about the study aims and explained that participation would involve talking about their perceptions and experiences of stress. Due to the perceived sensitivity of discussing stress, the recruitment strategy was limited to two attempted approaches to the participants.

Twelve doctors ( 3 male, 9 female) agreed to participate in the study. Two doctors (1 male, surgery; 1 female, medicine) withdrew due to existing work commitments making it impossible to arrange an interview timeslot within the study period. Ten doctors $(25.0 \%)$ were interviewed. Interviews took place after around 10 months of the participant's first year as a doctor. Although participants were in different placement settings (5 acute medicine, 4 emergency care, 1 surgery) all were in their final placement and had experienced an emergency care, medical and surgical setting. The study was approved by a UK National Health Service Ethics Panel (Northumberland Local Research Ethics Committee - 06/Q0902/26). An ethical consideration that was included, due to the nature of the subject area, was the concern that the study might trigger responses to stress in the participant. This may have arisen as the participant's awareness of their own stress increased during the course of the study or the participant might use the project as a vehicle for seeking help. To safeguard this, support service information was provided in information packs and during the project debrief. No adverse ethical issues occurred.

\section{Interview schedule}

Each doctor participated in a semi structured interview to discuss their views and experiences of stress. Discourse focused interviews are distinctive as they are more like a conversation. ${ }^{42}$ An interview schedule was developed based on earlier research findings and used for general topic coverage (See Appendix 1). The use of a schedule does not dictate the interview process and frequently the order was revised as a consequence of how the participant responded to questions. However, although the order of questioning was used flexibly, the content listed in the schedule was consistently covered throughout all the interviews. Typical questions asked were "Can you describe the last time you heard someone talk about being stressed at work?", "Do you think stress is part and parcel to your job as a doctor?" "If one of your colleagues was experiencing stress at work, what would the signs be?"

An independent researcher (NJT), not involved with the doctors' training, conducted the interviews. The use of an independent researcher was adopted to remove any role ambiguity that might have occurred, for example if the interviewer was a faculty member involved in the assessment of the doctor. Interviews lasted between 20-60 minutes and took place at an education centre, away from the workplace, but on the same site as the doctors' placement. Interviews were recorded with the consent of the participants and transcribed verbatim.

\section{Analysis}

The analytic framework was informed by the discourse analysis assumptions described above. The analytic process enabled the identification of interpretative repertoires that the doctors regularly and consistently drew upon. The social practices $^{38}$ that employing this talk achieved were then examined. The analytic process consisted of several stages; firstly, screening across transcripts for patterns of variability and consistency of how stress was talked about. Secondly, identifying what function talking about stress in that particular way might fulfil. One researcher coded all of the transcripts (NJT). Patterns that were identified were then reviewed by the other authors (MW,SC). There were only a few cases of disagreements often individual instances of coding which were easily resolved. In those cases agreement was reached through discussion between the three authors and also considering feedback from participant checking and feedback from independent researchers. 
In order to increase the credibility and dependability of the findings, assumptions were critiqued separately by four non-medical researchers who were independent of the project. Participant checking was also conducted through a series of workshops with FY1 and FY2 doctors and by providing an overview of findings to participants for feedback. The findings are not presented as a complete analysis but rather are intended to offer a starting point for considering a discursive framework for junior doctor stress. The present study presents an analysis of each of the repertoires. Our analysis is divided into sections which describe each interpretative repertoire in turn and provide detailed examples of the repertoire being used through interview extracts. With each repertoire some implications of the function of this talk are considered.

\section{Findings}

The focus of the data analysis was how the doctors constructed stress through their talk. We found that the doctors interviewed, when faced with direct questions around their own experiences of stress; typically normalised, deflected or trivialised their own experiences. Three interpretative repertoires that the junior doctors used in their talk about stress and stress experiences were identified; these have been titled the 'busyness repertoire' 'patient responsibility repertoire' and the 'good doctor' repertoire. The doctors most commonly used the busyness repertoire (with more variation in its usage) than the patient responsibility and good doctor repertoires. We will describe each of these in turn and provide interview extracts to demonstrate the repertoire usage, characteristics and possible function.

\section{Busyness repertoire}

The first interpretative repertoire was titled "busyness" and was most frequently employed in comparison to the other two repertoires. Often doctors used terms such as stressed and busy interchangeably when discussing a difficult day. This interpretative repertoire is characterised by an association with working demands, and intensity. These demands ranged from being on call, carrying a bleep and the general activity of the work.

"stress of having a bleep when you are on call and feeling harassed and being asked being phoned so often or being bleeped so often to do jobs you can't actually get on with the jobs you are doing and things building up and knowing that there are more sick patients that you can see at once and trying to work out how to prioritise and whether you need to call in help to see them or whether you can see them yourself within the sensible timeframe and I think of that as acute moments of stress". (Female, Medicine Placement - P113)

\footnotetext{
"when I feel that my time is under pressure and you feel you have a lot to do and have not got time to do it in and especially when nurses keep reiterating things they need doing and your like yeah I have only got one pair of hands." (Female, Medicine Placement - P111)
}

In the two extracts above both doctors employ the busyness interpretative repertoire. An evident characteristic of this is having control over work associated emotions such as being 'harassed' and the 'building up' of emotions. In drawing on the busyness repertoire the doctor constructs stress as something that they have no control over. Being bleeped, pressured by other staff or having too many patients are factors beyond their scope of control. Historically the role of the doctor has been associated with long hours and high demand resulting in high levels of stress. Constructing stress in this way serves a particular function for the doctor. In describing stress in these terms there is less risk of future criticism on their performance. It would be difficult for an onlooker to challenge how well the doctor is dealing with stress, and therefore question their performance, when the stress itself is beyond their control. Stress as busyness can be considered by the doctor as a socially acceptable way to talk about their stress as it avoids any need for accountability. In the extracts below the doctors make the distinction between stress as busyness and other stress in their role. These extracts were taken from the part of the interview when doctors were asked to elaborate on their views and experiences of stress. In the first examples after classifying stress as busyness and employing the interpretative repertoire consistently, the doctor devalues the impact by dismissing busy as 'fine' or 'not particularly stressful'. In the second extract the effect of busyness is normalised as something that would affect anyone.

\footnotetext{
"no its not busyness, busyness in itself is not particularly stressful, it is big decisions and taking responsibility for them and feeling you have done the wrong thing, and angry relatives and dying people. Busy is fine." (Female, Emergency Care Placement - P 104)

"I think a busy shift would be stressful for anybody I suppose. It is just a question of getting through it. While a sick patient is all encompassing and I think it gives you a different sort of stressed feeling, its really hard to explain. I think with a sick patient you would be stressed at the time but once you have got through it and got over it and its better whereas a busy day will leave you stressed out throughout the whole thing its only by going home and doing other things that you get over it. It is a different kind of thing I think". (Female, Emergency Care Placement - P126)
}

In summary, in constructing stress using the busyness repertoire the doctor is able to complete important social functions. Firstly, stress is constructed as out of the doctors' control and therefore they cannot be held accountable. The risk of potential criticism for not coping is therefore reduced. Secondly, stress is normalised in terms of something akin to all the other job demands, factors that have been historically associated with being a doctor. Stress is therefore constructed as a symptom of the common environment and not a reflection on individual performance and capability. Finally, stress is generalised not as an individual's concern but a doctors' concern. These experiences are 
therefore seen as something that all doctors face, rather than the failing of one individual.

\section{Patient responsibility repertoire}

Doctors used a second interpretative repertoire titled "the patient responsibility" as it was associated with doctors attributing the cause of stress to the responsibility of patient care and decisions. In the second extract above the doctor (P126) switches between busyness and patient responsibility repertoires. In the first extract above the doctor (P104) summarised the risk for the doctor in using this repertoire 'it is big decisions and taking responsibility for them and feeling you have done the wrong thing'. Here there is something at stake for the doctor, making the wrong decision. In the extract below further differences are highlighted between the first two repertoires, in particular that the doctors have a degree of control with patient responsibility compared to the lack of control in first repertoire. In the extract below the doctor constructs stress in terms of decision making. Noticeably the doctor talks through a process, which in contains self-doubt and concern over making the right decision.

\begin{abstract}
"I class that [stress] under the responsibility for patients. On a day to day basis you have to make decisions about are they getting better or worse if they are getting worse what do you do, do you do nothing? Something? If you do something what do you do? how much worse are they? Can you cope with it? Do you need to call for help? Immediately? Do you need to try a few things first then call for help." (Female- Medicine Placement P113)
\end{abstract}

In constructing stress in this way, an onlooker is in a position to challenge the doctor in how they deal with the decisions that they made and how they coped with that difficult situation. All of these are within their realms of control. In using this interpretative repertoire how the doctors' individual performance is viewed becomes something at stake. One way in which the doctors addressed this risk was simply to use the repertoire less frequently, on some occasions this involved the doctor simply switching to the busyness repertoire at the earliest opportunity. A use of this interpretative repertoire involved emphasising how patient responsibility was an inherent element of the role. The doctor in the extract below demonstrates an extreme case of this by suggesting that without these stressful elements the job itself would be less valuable

"I think stress comes alongside responsibility and if you didn't have any responsibility in the job it would be boring and you wouldn't enjoy it and it wouldn't be rewarding so you have to take the responsibility so you have to take a certain amount of stress with that." (Female, Medicine Placement - P108)

In constructing stress in this manner the interpretative repertoire serves as a further function of accountability. The close association between stress and the intrinsic value of the role works to normalise stress as an issue, for the medical profession as a whole, rather than a failing of individual performance. Furthermore, stress is constructed as something that is a job requirement in order to attain valued elements of the role. Without stress the job would be boring. In summary, in using the patient responsibility repertoire the doctor is acknowledging the stress associated from providing patient care and related decision making. However, constructing patient care as stressful presents an inherent risk for the doctor as it offers the opportunity for value judgement on their performance. Therefore, a function of the interpretative repertoire therefore is to offer a means of subverting possible challenges through normalising stress as a professional issue which is essential for intrinsic job satisfaction.

\section{The good doctor repertoire}

The third interpretative repertoire was titled "the good doctor" as it recognised the instances where stress and the management of stress were associated with being a good doctor. This complements the two earlier repertoires. The repertoire encompasses the social ideal of the doctor as the model professional, who copes with stress, while positioning those who don't as not good doctors. In this repertoire the talk is about what is expected of the doctor and how the stress itself is an inherent underpinning of the job. The good doctor is someone who copes with stress as the doctor stipulates below in the extract.

\footnotetext{
"I think if you are not coping well with stress you probably are not going to do yourself justice and I think you are more likely to make mistakes just as if you are really tired you are more likely to make mistakes em I don't think necessarily if you are stressed you a worse doctor but if you are very stressed and your minds not focusing on what you are doing there is a danger that you might not get it right. I think it does depend on how you are coping with stress." (Female, Medicine Placement - P135)
}

In the extract above, stress is constructed as something that is fine to experience as a doctor as long as you are doing a good job. Therefore, performance and stress are viewed as related. Speakers using this interpretative repertoire are constructing stress as something that is part of what good doctor deals with. And by that logic, those that do not cope with stress are not good doctors. This can be seen in the extracts below as the doctors describe stress as the natural response to the difficulty of the job. However, being a good doctor means that the individual deals with it.

\footnotetext{
"we are dealing with serious stuff, people die. We are dealing with people's lives and obviously it is going to be stressful and if you didn't if you were not able to respond to stress appropriately then you wouldn't be a very good doctor so I don't think it is a particularly negative or positive it is just one of those things" (Female, Emergency Care Placement - P128)
} 
"you are dealing with some very horrible situations and if you didn't react to them in any way and it didn't affect you then I don't think you would be a very good doctor." (Female, Emergency Care Placement - P111)

The association between coping and performance is more complex that a simple causal relationship. The extent that stress is part of the role is deep seated and speakers using this repertoire talk about stress not as an effect of the job but as a requirement of the role. The doctor in the extract below indicates that a doctor who is not stressed is someone who is failing in how they care and is therefore not a good doctor.

\begin{abstract}
"I think if you were not stressed about your job then it would either mean it would either be a personality thing but it might mean that you didn't care enough. I think I think there has to be a little bit of concern about problems about potential problems because if you weren't worried about them that could make you a bad doctor by definition, not always, but if you didn't care about the consequences then that would not be a good thing." (Female, Medicine Placement - P108)
\end{abstract}

Within this repertoire stress is constructed alongside expected behaviours of the good doctors dealing with stress. In the extract below we see a doctor describing someone who is not coping with stress and should be seeking help (something they also admit is not something as a profession they do well). However in doing this they define how they would be considered as good or bad.

\begin{abstract}
"its not a question of thinking oh that person is getting stressed they are not as good as me or whatever or anything like that at all. I think its more to do with if you see if someone is getting stressed in a situation you try and help them out to some extent. If someone is getting stressed because they are not really sure what they are doing then they need to be able to ask for help and that is something that doctors traditionally have not been good at doing. I just want to help out the other house officers. I would think badly of them if they were in a situation where they were out of their depth and they took ages to take a decision and they didn't do anything. I would think badly of them if they didn't realise they were out of their depth and didn't ask for help." (Male, Emergency Care Placement - P123)
\end{abstract}

In summary the repertoire constructs stress as something that is a prerequisite of the role of the doctor. The good doctor is someone who is aware and able to cope appropriately while a doctor who is not good is not able to cope or does not acknowledge the effect of stress. The repertoires allow a construction of stress as normalised as part of the role, however it also serves to reinforce the expected right and wrong way to deal with stress in medical education.

\section{Discussion}

To better understand socio-cultural influences of stress in medical education, FY1 doctors were interviewed in order to examine how new doctors talk about stress. There is a wealth of evidence that indicates that junior doctors are likely to experience heightened levels of stress. ${ }^{1-8}$ Despite this participants consistently normalised, deflected or trivialised their own experiences of stress which is consistent with other studies that indicate a reluctance by doctors to discuss their own stress. ${ }^{11,16,17}$

Within the medical education setting a consistent pattern of emergent stress discourses were identified that were displayed through three interpretive repertoires; busyness, patient responsibility and good doctor. These findings illustrate the consistent construction of stress that may reflect some of the socio-cultural elements attributed to the hidden curriculum in medical education. ${ }^{34}$ These are accepted constructions of stress in this context and findings have notable implications as elsewhere it has been shown that stress discourses shape how employees complain about stress and how the organisation responds. ${ }^{35}$

The busyness interpretative repertoire of stress was characterised as working demands and intensity and reflects our historical perception of the demanding junior doctor role often reported..$^{1-8}$ Discursively this has also been found in female clerical workers. ${ }^{32}$ This repertoire could serve as a gate-keeper for discussing stress; as usage of these discourses limits a potential discussion to a level of simply reflecting on environmental issues, which is often the case. ${ }^{21}$ Therefore, not personally coping or the impact of stress at an individual level are not fully considered when these discourses are employed. Apart from providing the doctor with a means of diverting conversation about potential challenge by listeners, about their ability to manage stress, it also hinders many approaches to intervention which rely on being initiated when a doctor reports their stress.

In the patient responsibility repertoire, stress was associated with doctors attributing the cause of stress to the responsibility of patient care and related decision making. Although the relationship between stress and facets of patient care has been highlighted previously, ${ }^{4}$ this association with environmental based causes is more frequently reported. ${ }^{43,4}$ The patient responsibility repertoire allows the doctor to construct stress as exclusive, or particular, to the medical profession. The use of professionally-specific stress discourses functioning as rhetorical devices to manage accountability have been reported in other professions. ${ }^{31-33}$ The use of repertoires here can offer a similar function; serving to normalise the experience as a professional consequence that all face, rather than an individual failure to cope. A further possible feature of this is that the repertoire is particular to the profession. Therefore, to a degree can function to exclude non-medics from engaging in a detailed dialogue around it. This could also serve to limit the ability of a non-medic to challenge any failure in coping and subsequently act as a further stake management tool. The good doctor repertoire of stress is formed around the idealised notion of the doctor as the model professional who copes with stress; while constructing someone who cannot cope as not being a good doctor. Doctors' concerns of acquiring negative labels have been reported previously. ${ }^{12,21}$ Therefore it is not unsurprising that this manifests in the 
day to day talk around stress. Support for the good doctor interpretive repertoire has been found elsewhere; the good doctor narrative being adopted by medical students, suggesting some earlier usage in medical education. ${ }^{44}$ The notion of the good employee has been identified in other professions such as teaching. ${ }^{33}$ The association with identity has also been shown in other professions. What becomes at stake is the relinquishing of an established and valued identity, being a doctor to a role that is considered aversive and could lead to a loss of integration with colleagues. ${ }^{31}$ Employment of this repertoire may also be associated with identity claims; the use of categories and membership categorization devices have been shown to be used in denials of accusations. ${ }^{45}$ The use of categories such as 'good doctor' formulates an identity with associated assumed characteristics; such as being able to cope, presentation of being able to cope, reacting to stimuli in a particular way and establishing a rationale for behaviour. However the converse was also seen in our study, where doctors also referred to not being a good doctor if difficult experiences didn't affect the doctor to some extent. The discourse of the 'good doctor' is therefore far more complex than simply not letting it affect you and requires further examination.

The interpretive repertoires identified within the study reflect common cultural constructions of the doctor as burdened by over work ${ }^{43}$ and the unique demands of patient care $^{4}$, while remaining the model good doctor. ${ }^{19}$ These findings illustrate the importance of considering stress within its socio-cultural context, as is clear within other occupations, ${ }^{32}$ and taking consideration of potential factors associated with the hidden curriculum. ${ }^{34}$ Collectively these interpretative repertoires served to perform particular social functions for the doctors that involved managing stake and accountability. They facilitate a process of impression management; that of being able to cope. The use of the interpretative repertoires allowed doctors to normalise stress as something that is part of the environment or something that all medical professionals must deal with. Similar findings have been found elsewhere in other occupational contexts. ${ }^{30,31,33}$ The identification of such practices within medical education reinforces the usage of interpretive repertoires in occupational settings with clear identities. Furthermore, the findings reinforce the influence of sociocultural factors present in medical education ${ }^{34}$ and highlights that stress within medical education cannot be effectively examined without also considering these important contextual factors.

\section{Implications for practice}

In general these findings have important implications for interventions intended to prevent or alleviate stress in medical education. If existing interpretative repertoires, centred around the effectiveness of individual's stress management, dominate then attempts to improve the doctors' experiences of stress will be continually undermined. Goffman ${ }^{28}$ made the distinction between those expressions given and given off and our findings demonstrated through use of interpretive repertoires how expressions given are managed. Therefore, Medical educators need to consider their awareness of how these discourses are utilised and possibly employed in a way that might marginalise or stigmatise doctors. Clinical role models and influential educators may need to be more sensitive to the stress discourses consistently adopted, in curriculum, policies and daily interactions, if they serve to simply mask the impact of stress or hinder help-seeking behaviour. A culture where stress is discussed solely in terms of an environmental issue, rather than with respect to how an individual copes or has difficulty in coping, is unlikely to enable any depth of dialogue on issues around stress. However, these findings point to an opportunity to construct alternative discourses than can aid organisational interventions. Constructing stress as a professional consequence, that is inherent to the role, could permit a culture were stress can be openly discussed and serve to facilitate earlier help-seeking. Therefore coping, or not coping, could be viewed as a typical experience, and the seeking of support could be viewed as commonplace rather than labelled as something that only the doctors who are not 'good' have to undertake.

The presence of a stress discourse within medical education has implications for interventions intended to prevent or alleviate stress. Consistent stress discourses have shown to shape how employees complain and organisations respond to stress complaints. ${ }^{35}$ For example, social and cultural prejudices may influence the disclosure of being affected by stress within particular organisational contexts. Employees may simply not use stress management strategies because they are resisted in the workplace culture or their position within the hierarchy. ${ }^{32}$ The medical profession is particularly susceptible to using (ineffective) coping strategies that minimise perceptions/impacts of stress such as responding to stress by continuing to work, relying on non-formal consultations and attempting to mask effects. ${ }^{15-}$ ${ }^{17}$ Therefore it is unsurprising that the discursive strategies used, as a means of presenting coping and impression management, contributed towards the function of maintaining a position as the model medical professional. How this varies between those doctors who effectively cope with stress and those who do not requires further research. However, inevitably the effectiveness of coping alongside managing this impression will mediate doctors' help seeking behaviour and any future take up of available support services.

\section{Study limitations}

The strength of the study is the focus on the doctors' stress experiences in the day to day professional context, which is an important direction of work and contrasts the large body of self-report studies on the prevalence of psychological morbidity that exists with context factors largely omitted. The current study did not attempt to measure the stress 
levels of the doctors themselves, individual differences or how they coped with stress. A factor which may have influenced our findings was that data collection was derived from interview methodology conducted by someone not involved in the medical education training. An interview which has been conducted by a member of faculty might have created a far more acute presentation of impression management as the participants professionalism might have been considered more at stake. For example, a junior doctor being interviewed may not wish to disclose anything that could view them negatively to a faculty member who may be involved in their on-going performance assessment. They may be even less likely to disclose not coping if this was something that might influence how their performance was viewed by the faculty member.

Some discourse analysis theorists increasingly have emphasised data collected from naturalistic setting. ${ }^{46}$ Such an approach may have allowed us to generalise our discussion further, unpack the use of categories such as 'the good doctor', and examine the data to a greater degree. There remains a need to expand this corpus of work through methods that allow an examination of stress discourses beyond the current study settings.

These findings are undoubtedly limited in scope due to the small, female skewed sample and single site design. Some of the findings of discursively constructing busyness and maintaining degrees of social acceptability are similar to those reported in female clerical workers. ${ }^{32}$ However, our intention was not to present representative findings but to highlight the insight that the introduction of a nontraditional approach such as discourse analysis can offer. Due to the absence of studies which have taken this analytic position in relation to stress in medical education, these results remain valuable as indicative of future research directions to pursue.

\section{Future research directions}

The current study provides indicators for further on-going examination of the extent to which these repertoires are used more broadly in medical education career and other contexts. The current study limitations of the underrepresentation of male doctors or those currently in surgical placements could be one particular area of examination. Future research designs based around the range of discourse analytic approaches (e.g. Conversational Analysis, Discursive Psychology, and Critical Discourse Analysis) offer new directions, particularly those that might focus on the analysis of naturalistic interactional data. ${ }^{46}$ Examining how stress discourses are interwoven into routine life might include specific contexts such as; recordings from telephone help-lines or therapy sessions; settings where stress might influence performance outcomes such as fitness to practice hearings or reviews of doctor who are failing to meet expected performance standards; settings typically considered stressful such as ward rounds, particular acute or complex specialty settings; and media and organisational portrayals of stress in medical education. At an organisational level an examination of how stress is constructed by medical educators, across the curriculum and in education settings would be an essential next step.

\section{Conclusions}

In summary, our initial study demonstrates that doctors remain avoidant when talking about personal stress and rely upon at least three distinct but related interpretative repertoires when talking about their views and experiences of stress. The use of such repertoires within medical education supports similar findings in other professions. The use of stress interpretative repertoires acts as impression management of constant professionalism which enables the individual to discuss stress and experiences of stress without risk of judgement that any inability to cope with stress reflects on their abilities as a doctor in general. This study has taken a marked shift away from a traditionally quantitative research field and demonstrated the potential additional insight than can be created through adopting qualitative approaches. Further work is required, particularly in considering whether such discourses are consistent along the career pathway, different specialities and educational settings.

Medical educators need to be more aware of how different stress repertoires are adopted by doctors. The presence of these dominant discourses may risk the creation of environments where the impact of stress is dismissed, or that those admitting to not being able to cope are marginalised. In such environments interventions, designed to prevent or alleviate stress are unlikely to be effective and high levels of stress will likely continue to be reported in medical education.

\section{Conflict of Interest}

The authors declare that they have no conflict of interest.

\section{References}

1. Alexander D, Monk JS, Jonas AP. Occupational stress, personal strain, and coping among residents and faculty members. Journal of Medical Education. 1985;60(11):830-9.

2. Asai M, Morita T, Akechi T, Sugawara Y, Fujimori M, Akizuki N, et al. Burnout and psychiatric morbidity among physicians engaged in end-of-life care for cancer patients: a cross-sectional nationwide survey in Japan. Psycho-oncology. 2007;16(5):421-8.

3. Butterfield PS. The stress of residency. A review of the literature. Archives of Internal Medicine.1988;148(6):1428-35.

4. Firth-Cozens J. Emotional distress in junior house officers. British Medical Journal. 1987;295(6597):533-6.

5. Hsu K, Marshall V. Prevalence of depression and distress in a large sample of Canadian residents, interns, and fellows. The American Journal of Psychiatry. 1987;144(12):1561-6.

6. Lue B-H, Chen H-J, Wang C-W, Cheng Y, Chen M-C. Stress, personal characteristics and burnout among first postgraduate year residents: a nationwide study in Taiwan. Medical Teacher. 2010;32(5):400-7.

7. McManus IC, Keeling A, Paice E. Stress, burnout and doctors' attitudes to work are determined by personality and learning style: a twelve year longitudinal study of UK medical graduates. BMC Medicine. 2004;2:29.

8. Thompson N, Corbett S, Larsen L, Welfare M, Chiappa C. Contemporary experience of stress in UK Foundation level doctors. The Clinical Teacher. 2009;6(2):83-6 
9. Schwenk TL, Davis L, Wimsatt LA. Depression, stigma, and suicidal ideation in medical students. JAMA: the Journal of the American Medical Association. 2010;304(11):1181-90.

10. Ratanawongsa N, Wright SM, Carrese JA. Well-being in residency: a time for temporary imbalance? Medical Education. 2007;41(3):273-80. 11. Baldwin PJ, Newton RW, Buckley G, Roberts MA, Dodd M. Senior house officers in medicine: postal survey of training and work experience. British Medical Journal. 1997;314(7082):740-3.

12. Caplan RP. Stress, anxiety, and depression in hospital consultants, general practitioners, and senior health service managers. British Medical Journal. 1994;309(6964):1261-3.

13. Chambers R. Health and lifestyle of general practitioners and teachers. Occupational Medicine. 1992;42(2):69-78.

14. Fox FE, Doran NJ, Rodham KJ, Taylor GJ, Harris MF, O’Connor M. Junior doctors' experiences of personal illness: a qualitative study. Medical Education. 2011;45(12):1251-61.

15. Baldwin PJ, Dodd M, Wrate RW. Young doctors' health--I. How do working conditions affect attitudes, health and performance? Social Science \& Medicine. 1997;45(1):35-40.

16. Pullen D, Lonie CE, Lyle DM, Cam DE, Doughty MV. Medical care of doctors. The Medical Journal of Australia. 1995;162(9):481, 4.

17. Kay M, Mitchell G, Clavarino A, Doust J. Doctors as patients: a systematic review of doctors' health access and the barriers they experience. British Journal of General Practice. 2008;58(552):501-8.

18. Hayward P, Bright JA. Stigma and mental illness: a review and critique. Journal of Mental Health. 1997;6(4):345-54.

19. Sritharan K. Should doctors always admit mistakes? BMJ Careers. 2005;331:109-10.

20. Chew-Graham CA, Rogers A, Yassin N. 'I wouldn't want it on my CV or their records': medical students' experiences of help-seeking for mental health problems. Medical Education. 2003;37(10):873-80.

21. McGowan Y, Humphries N, Burke H, Conry M, Morgan K. Through doctors' eyes: a qualitative study of hospital doctor perspectives on their working conditions. British Journal of Health Psychology. 2013;18(4): 874-91.

22. Bicknell M, Liefooghe A. The art of stress. Journal of Occupational and Organizational Psychology. 2006;79(3):377-94.

23. Newton T. Managing stress: Emotion and Power at work. London: Sage; 1995.

24. Pollock K. On the nature of social stress: production of a modern mythology. Social science \& medicine. 1988;26(3):381-92.

25. Abbott A. Positivism and interpretation in sociology: lessons for sociologists from the history of stress research. Sociological Forum. 1990;5(3):435-58.

26. Doublet S. The stress myth: Science \& Humanities Press Chesterfield, MO; 2000.

27. Irvine D. The performance of doctors.1. Professionalism and selfregulation in a changing world. British Medical Journal. 1997;314(7093): 1540-2.

28. Goffman I. Presentation of self in everyday life. Garden City, New
York: Doubleday/Anchor; 1959.

29. Tetlock PE. Accountability. The neglected social context of judgements and choice. In: Cummings LL, Cummings BM, editors. Research in organisational behaviours. Greenwich, CT: JAI Press; 1985. p. 297-332.

30. Scott JW. Deconstructing equality-verses-difference: or, the use of postructuralist theory for feminism. In: Hirsch M, Keller EF, editors. Conflict in feminism. New York: Routledge; 1990. p. 134-48.

31. Dick P. The social construction of the meaning of acute stressors: a qualitative study of the personal accounts of police officers using a stress counselling service. Work and Stress. 2000;14(3):226-44.

32. Harkness AMB, Long BC, Bermbach N, Patterson K, Jordan S, Kahn H. Talking about work stress: discourse analysis and implications for stress interventions. Work and Stress. 2005;19(2):121-36.

33. Hepburn A, Brown SD. Teacher stress and the management of accountability. Human Relations. 2001;54(6):691-715.

34. Lempp H, Seale C. The hidden curriculum in undergraduate medical education: qualitative study of medical students' perceptions of teaching. British Medical Journal. 2004;329(7469):770-3.

35. Barley SR, Knight DB. Toward a Cultural Theory of Stress Complaints. Research in Organizational Behavior. 1992;14:1-48.

36. Willig C. Introducing qualitative research in psychology: Adventures in Theory and Method. Maidenhead: Open University Press; 2008.

37. Taylor S. Locating and conducting discourse analytic research. In: Wetherell M, Taylor S, Yates SJ, editors. Discourse as data: a guide for analysis. London: Sage Publications Ltd; 2001. p. 5-48.

38. Potter J, Wetherell M. Discourse and Social Psychology: Beyond Attitudes and Behaviours. London: Sage; 1987.

39. Parker I. Discourse dynamics: critical analysis for social and individual psychology. London: Routledge; 1992.

40. Fairclough N, Wodak R. Critical discourse analysis. In: Van Dijk TA, editor. Discourse as social interaction (Discourse studies: a multidisciplinary introduction, Volume 2). London: Sage Publications; 1997.

41. Burr V. An introduction to social constructionism. London: Routledge; 1995.

42.Potter J, Wetherell M. Discourse analysis. In: Smith J, Harre R, van Langerhove L, editors. Rethinking methods in psychology. London: Sage Publications Ltd; 1995. p. 80-92.

43. Coomber S, Todd C, Park G, Baxter P, Firth-Cozens J, Shore S. Stress in UK intensive care unit doctors. British Journal of Anaesthesia. 2002;89(6):873-81.

44. Monrouxe LV. Negotiating professional identities: dominant and contesting narratives in medical students' longitudinal audio diaries. Current Narratives. 2009;1:41-59.

45. Stokoe E. 'I'm not gonna hit a lady': conversation analysis, membership categorization and men's denials of violence towards women. Discourse and Society. 2010;21(1):59-82.

46. Potter J, Hepburn A. Discursive psychology as a qualitative approach for analysing interaction in medical settings. Medical Education. 2005;39(3):338-44.

Appendix: Interview schedule

1. We plan to schedule the interview as follows:

Introduction

What we will be doing today and how your information is used

Signing of consent forms

Warm-up questions

Main interview

Debriefing
10- 15 minutes

45- 50 minutes

2. What we will be doing today and how your information is used

When we start the interview I will be asking you questions about your experiences on the Foundation Programme. I would like to encourage you to express your opinions and feelings freely. Please be reassured that there are no right or wrong opinions, it is important that we get as honest opinions as possible.

The interview will be audio-taped and then transcribed so we can analyse the content. The transcription will be done so that no names appear in the transcription, neither your name nor people you might mention. If the context of reply allows for identification of any specific person we will modify the text such that identification is made impossible. After transcription the audio-tape will be deleted and your name, or any person you may have mentioned during the session, 
I will send you a first draft of the analysis in order for you to have the option to comment on the content if you wish. I will also send you a copy of the final analysis that will be contained in the report.

3. Signing of consent forms

\section{(INTERVIEWER CONFIRMS THAT THE PARTICIPANT HAS SIGNED THE CONSENT FORM)}

If you have not already returned a consent form prior to the session we would like you to sign a consent form prior to commencing the interview. By signing you will be agreeing to respond to our questions as discussed. You may withdraw your participation any time, even after the end of the interview. All you would have to do is inform us. The information sheet we have given you provides more detailed information about participation and withdrawal. Do you have any questions about taking part in this interview?

If you would like to continue your participation under these conditions please fill in and sign the consent form now.

4. Warm-up questions

- If you feel ready to start I will now ask you a few simple questions, followed by more open questions, which will give you an opportunity to give me your opinion.

I will now start the audio-taping.

- Please tell me where your current placement is based and what other placements have you completed this year?

\section{(INTERVIEWER STATES DATE AND PARTICIPANT NUMBER FOR THE RECORDING)}

\section{Main interview}

Now I will ask you some questions that focus on your experiences of stress in the workplace and your views towards it as a Doctor.

\section{OPINIONS OF STRESS}

- What is your view of stress?

- Where do you think your views of stress have come from?

- What things around stress have you been taught either during medical school or whilst on the Foundation Programme?

- What influences outside of medical training might have had an influence on your views of stress?

\section{YOU'RE EXPERIENCE OF STRESS}

- Within past research and also through the popular media there is a portrayal of the stressed Junior Doctor, how accurate do you think is this portrayal?

- How does that image reflect your experiences?

- How stressful would you consider your work?

- Ok, so what makes your work stressful?

- When you are feeling stressed how do you react?

- How effective do you think that way of reacting is as a means of responding to stress?

- What affect does stress in the workplace have on you?

\section{STRESS AS A DOCTOR}

- There is often a comment made that as a doctor stress is part of the job and good doctors just deal with it. How would you respond to such a comment?

- Are there particular things in the context of your role as a House Officer that you would consider as stressful compared to other doctors?

- When people in general get stressed they often have an emotional reaction, do you think that this is the same for doctors?

- What differences are there in how you handle stress whilst around a patient, compared to with a peer or a more senior colleague?

\section{REACTING TO STRESS}

- How do you think most Junior Doctors react to stress?

- How would you expect a doctor who is suffering from stress to react to it?

- Have you ever seen a colleague react to stress or workplace pressure which in your eyes is in an inappropriate way?

- What lasting impression did this leave with you?

- What affect do you think it had on others who witnessed this?

- What kind of expectation do you think there is on how Doctors should handle the stress?

- Do you think there are different expectations on how Doctors should handle stress compared to other professions?

- If yes, why?

- Where do you think that expectation comes from?

- Can you think of an example where you have seen this in your colleagues?

- Is there an expectation of how you should react?

- What differences are there between what stress the JD have to deal with compared to that of Consultants or registrars how would they react?

- Does that influence how Junior Doctors react?

\section{RECOGNISING STRESS IN PEOPLE}

- You have talked about your views of stress, how recognisable do you think stress is in people you work with?

- Do you think other would recognise it in you?

- How do you recognise it in yourself?

- What do you do? 
- STRESSFUL WORKPLACE

- Where do the stressors come from within the hospital?

- What are the particular situations that you might face that you would consider as stressful?

- How frequent are these?

- What was the transition from medical school to the foundation school like?

- How does working on the Foundation Programme compare to the Stresses of medical school?

- How do you think did medical school prepared you for pressures of the Foundation Programme?

- Of the placements completed how would you compare the working environments?

- What's your experience of surgery, how stressful have your experiences been?

- Emergency Care is often considered the most stressful placement to work in? how does this compare with your experience?

- What aspects make it stressful?

- How does this placement compare with Surgery/ Medicine

- Why are these placements different?

SUPPORT

- What support is available to a Junior Doctor trying to cope with Stress?

- What do you think would be your reaction if a colleague confided in you that they were not coping and were themselves stressed?

- How do you think you would feel in such a situation?

- What would be your concerns in that situation?

- Patient Care, Individual Welfare, competence, stigma?

- If you were feeling stressed who would you turn to for support?

- Why them?

DOCTOR AS PATIENT

- There is quite a lot of work written as to the difficulty of Doctors being patients, how difficult is it for a doctor to acknowledge they are stressed?

- Why?

RECOMMENDATIONS

- With respect to stress, is there anything that could be done that you think could benefit /improve the situation for foundation doctors? 